\title{
Evaluating of Training and Internship Programs of University Hospitals
}

\author{
Farzianpour Fereshteh ${ }^{*}$, Emami Amir Hossein ${ }^{2}$, Hosseini Shayan ${ }^{3}$ \\ ${ }^{1}$ Health Management \& Economic Department, School of Public Health, Tehran University of Medical Sciences, \\ Tehran, Iran \\ ${ }^{2}$ Internal Medicine Department, School of Medicine, Tehran University of Medical Sciences, Tehran, Iran \\ ${ }^{3}$ School of Electrical Engineering, Amirkabir University of Technology, Tehran, Iran \\ Email: farzianp@sina.tums.ac.ir
}

Received 16 April 2016; accepted 14 May 2016; published 17 May 2016

Copyright (C) 2016 by authors and Scientific Research Publishing Inc.

This work is licensed under the Creative Commons Attribution International License (CC BY). http://creativecommons.org/licenses/by/4.0/

c) (i) Open Access

\begin{abstract}
Objective: This study aimed to assess training and internship programs (courses) of basic and clinical sciences in hospitals based on surveying the students of Tehran University of Medical Sciences. Material and Methods: The present study was a cross-sectional one with survey descriptive designs. The data collection tool was a questionnaire with 14 five-point likert style items. The Research and Development Center of Tehran University of Medical Sciences surveyed all 185 students of training and internship programs, using a questionnaire with the Cronbach's alpha coefficient of $81 \%$, for the purpose of adjusting the education to the society's needs and improving its quality. Result: The mean scores of the assessment of training and internship programs were $3.32 \%, 2.98 \%, 3.38 \%$ and $3.29 \%$, respectively for theoretical classroom training related to practical training, mental, communicational and practical skills courses. The students' satisfaction rate regarding the quality of educational courses of training and internship programs was $50.2 \%$. Conclusion: Educational authorities have made necessary attempts to implement these programs and use potential resources for realizing the objectives and achieving the educational quality; however, they should make further attempts in this regard.
\end{abstract}

\section{Keywords}

Evaluating, Training and Internship Courses, Hospitals, University

\section{Introduction}

Every educational system, whether micro or macro, requires that: its training coursed be evaluated, educational

"Corresponding author.

How to cite this paper: Fereshteh, F., Hossein, E.A. and Shayan, H. (2016) Evaluating of Training and Internship Programs of University Hospitals. Health, 8, 658-663. http://dx.doi.org/10.4236/health.2016.87069 
development be planned and educational management be implemented. What is meant by educational management is the optimal use of resources in order to achieve the objectives of the educational system. In other words, educational management is the process of making both the learners and instructors satisfied concerning the fact that if what is expected from them is done thoroughly, it will cause the improvement of educational system [1] [2]. Assessing training and internship programs in hospital is one of the main duties of universities of medical sciences in the country, and the degree of occupational potencies and efficiency of the graduates of medical sciences fields to deliver treatment and health services for the purpose of promotion of the health level of individuals and society depends on the degree of accomplishing the objectives of the these courses and, if the educational programs are not designed and implemented, it can cause irreparable damages and hence harmful social, economic and cultural effects on the public, graduates, management and the prestige of universities.

The process quality is the degree of satisfaction with teaching-learning processes and another one (structural, organizational and back up process. The product quality refers to how much the go-between outputs of the system (results, semester exams, promotion from one grade to a higher one and soon). In other words, the degree of satisfaction with each one of the go-between outputs can represent the quality of educational system. The output quality refers to how much educational outputs (professors, the result of the researches and other scientific works and the specialized services offered) are satisfactory compared to the standards which have been determined before (or purposes and expectations). Consequences quality refers to the employment status of the professors (from the point of view of themselves, their parents, their employers and generally those receiving their services [1]-[3]. In this definition of "quality" the relevance of the professors, acquired capabilities and their usage are considered, and their effectiveness in economic, social and cultural activities emphasized.

In addition to definitions of quality based on five factors (Input, Process, Output, Outcome, Impact) of educational system, recently quality has been defined as value added. In this definition, the quality of an educational system refers to the statue of the professors of the system, considering their knowledge, attitude and acquired capacities, and it should be possible to assign the present level of their repertoires, capacities and attitude to the educational system. In other words, concerning value added educational system has a high quality if it can be said that the scientific and practical qualification and the attitude of the professors have been acquired through gaining experience during education process. The concept of quality as value added is rather new, and there is still no suitable way to measure it [2]. The most important procedure which has been used is controlling the quality of education (education with total quality). Here, control refers to a procedure which measures the current performance and directs it in order to accomplish the intended objective [3] [4]. In this way, the education quality control is considered as measurement of current educational performances and directing them in order to achieve the educational objectives, and this procedure is feasible through Total Quality Management. Total Quality Management of an educational system doesn't simply think of the quality concerning accomplishment of objectives but takes the quality of all the elements and activities of the educational system into consideration [1]-[4]. In order to identify and measure effective factors in learning, it is necessary to evaluate the quality and effectiveness of educational efforts. Nowadays appropriate tests and methods are used to evaluate educational efforts in training and internship courses [3]-[7]. In a study conducted by Saif, Bazargan, Farzianpour et al., it was reported that evaluation of training and internship courses had an effective role in educational quality [5]-[9].

Educational evaluation of training and internship courses in the forms of Formative Evaluation and Summative Evaluation is one of the main duties of the universities of medical sciences in the country. In formative evaluation the emphasis is placed on the program process and informing educational program producers of the defects in order for them to be modified [10] [11].

The purpose of the present study was assessing training and internship programs of basic and clinical sciences in hospitals based on surveying the students. Special objectives were assessing the students, satisfaction with theoretical classes relevant to applied education, teaching mental, communicative and practical skills, training and internship time, the students, contribution, teaching medical ethics, social ethics, wards, equipment and devices, educational devices and facilities in wards, welfare facilities and the students, suggestions and criticisms.

\section{Material and Methods}

The present research is a descriptive cross-sectional study. The data collection tool was a questionnaire with 14 five-point Likert style items. To conduct the study, the Research and Development center of Tehran University of Medical Sciences surveyed all the students (185) of training and internship courses in 2011, using a ques- 
tionnaire with the cronbach's alpa coefficiency of $81 \%$ for the purpose of adjusting the education to the society's needs and improving the quality of education. Validity and reliability of this questionnaire was approved By 30 experts in health care management and medical education in Tehran university of Medical sciences.

To provide the data collection toll, it was tried that the variables under the study be determined in agreement with the objectives and questions of the research. For this purpose, before providing the data collection tool, a table was prepared, which specified the variables of each of the study questions and based on which the tool was provided. To provide the face validity of data collection tool, the questionnaires were reviewed by experts in basic and clinical sciences and their ambiguities and defects were removed, such as direct and unclear questions. Designing appropriate questions with phrases with the least ambiguity is the essential condition for questionnaire validity. In order for the questionnaires to have scientific validity, the procedure Content Validity was used. The questions were based on available books and studies [5].

Concerning data collection tool reliability after the questionnaires were provided based on the formulated items, surveying the board members of the university, the ambiguities of some of the items were identified and then removed. Then the final data collection tool was determined. In order to analyze the data, after they were collected, descriptive and analytic statistic was used.

The Fox pro was used both to feed the data in to the computer and to edit them, using SPSS 10 software. The data collected in the study were converted in to quantitative indices and then they were compared and the results were recorded in the related tables. To compare the data in terms of the case, ANOVA Test and $\mathrm{X}^{2}$ distribution method were used.

\section{Results}

The population under the study consisted of 185 students of basic and clinical sciences, who were taking training an internship course in hospitals affiliated to medical sciences universities of Tehran $36.6 \%$ of the students were male and $62.3 \%$ female. The mean score of the whole course, standard deviation and variation range were $16.03 \%, 1.33$ and 12.5 - 18.4 respectively.

In this survey the students mentioned educational managers, on-time presence and qualification of the teachers as the most important strong point of the course (85.9\%) (Table 1$)$.

Ninety one of the students (49.2\%) were satisfied with theoretical classes related to practical education, mental, communicative, attitudinal and practical skills and generally educational and programs instruction, teaching and learning process. The percent of the students, satisfaction with the war's devices and equipment related to the practical education and educational aid facilities in the wards and welfare facilities were $48.6 \%$ and $85.9 \%$ respectively. Concerning special educations such as medical and social ethics $49.2 \%$ and $49.8 \%$ of the students were satisfied respectively they had good opinion about internship time and educational activities ( $49.8 \%$ and 49.8\%). 3.32\%, 2.98\%, 3.38\% and 3.29\% were the percents obtained concerning theoretical classes related to practical education, mental skills, communicative skills and practical skills respectively The students, satisfaction with the quality of educational programs in training and internship courses was 50.2\% (Table 1, Table 2). To compare the data on the basis of ANOVA and chi-square distribution methods were used. The results reported that the satisfaction of theoretical and practical tests with Clinical education was a significant relationship satisfaction $(\mathrm{P}=0 / 0001)$.

But demographic characteristics, physical space and time allotted for training sessions and teaching aids were not significantly associated with satisfaction in training $(P=0 / 59)$.

\section{Discussion}

A training and internship course is a process in which the students attend the hospital and try to gradually acquire experience and through the acquired experiences and logical reasoning make their mind ready to find solutions to patients, problems. To achieve efficient clinical education, it is necessary that the current educational status be evaluated continually and its strong and weak points be identified [4]. Since one of the good ways to recognize the educational quality of basic and clinical sciences is surveying the learners, in order to find out how much trainees and inters of Tehran University of Medical Sciences are satisfied with the services de lived to them and also factors affecting their level of satisfaction, a cross-sectional study with descriptive designs was conducted, using a self-played questionnaire, to investigate their opinions. Factors affecting their complete or relative satisfaction or their dissatisfaction with the educational programs concerning theoretical, mental, 
Table 1. Evaluating of training and internship courses of the students of Tehran University of Medical Sciences.

\begin{tabular}{cccccc}
\hline Title & Satisfaction (\%) & Dissatisfaction (\%) & Average & Standard deviation & Total (\%) \\
\hline Teachers on-time presence & $159(85.9)$ & $26(14.1)$ & 2.01 & 0.67 & $185(100)$ \\
Internship length & $92(49.8)$ & $93(50.2)$ & 3.91 & 0.77 & $185(100)$ \\
Teachers, educational activities & $92(49.8)$ & $93(50.2)$ & 2.98 & 1.22 & $185(100)$ \\
Educational programs & $159(85.9)$ & $26(14.1)$ & 2.01 & 0.67 & $185(100)$ \\
Educational equipment & $90(48.6)$ & $95(51.4)$ & 3.07 & 1.14 & $185(100)$ \\
Welfare facilities & $159(85.9)$ & $26(14.1)$ & 2.01 & 0.67 & $185(100)$ \\
Educational quality & $93(50.2)$ & $92(49.8)$ & 2.01 & 0.67 & $185(100)$ \\
Students, contribution & $90(48.6)$ & $95(51.4)$ & 3.07 & 1.14 & $185(100)$ \\
Responsibility towards the students & $93(50.3)$ & $92(49.8)$ & 2.01 & 067 & $185(100)$ \\
Medical ethics & $91(49.2)$ & $94(50.8)$ & 3.3 & 1.03 & $185(100)$ \\
Social ethics & $92(49.8)$ & $93(50.3)$ & 2.85 & 1.24 & $185(100)$ \\
\hline
\end{tabular}

Table 2. Evaluating of training and internship courses of the students of Tehran University of Medical Sciences (educational skills).

\begin{tabular}{|c|c|c|c|c|c|}
\hline Title & Satisfaction (\%) & Dissatisfaction (\%) & Average & SD & Total (\%) \\
\hline Theoretical classes & $91(49.2)$ & $94(50.8)$ & 3.32 & 0.95 & $185(100)$ \\
\hline Intellectual skills & 92 (49.8) & $93(50.2)$ & 2.48 & 1.22 & $185(100)$ \\
\hline Attitudinal communication \& skills & $93(50.2)$ & $92(42.8)$ & 2.48 & 0.99 & $185(100)$ \\
\hline Operational skills & $89(48.1)$ & $96(51.2)$ & 2.29 & 1.02 & $185(100)$ \\
\hline
\end{tabular}

attitudinal, communicative and practical skills was investigated. The extent of the students, satisfaction with the quality of educational programs in training and internship courses was 50.2\%. Their level of complete or relative satisfaction with clinical education during internship and that of the provided education were $49.8 \%$ and $85.9 \%$ respectively. There was a significant relationship between satisfaction with theoretical and practical tests and that with clinical education $(\mathrm{P}=0.0001)$.

Three factors, i.e. the number of interns, familiarity with prevalent diseases and the existence of a developed educational program, were factors affecting the interns' satisfaction. In this study demographic factors, work setting, the length of the time devoted to training, the instructor, using educational aids didn't have a significant relationship to the satisfaction of the people under the study $(\mathrm{P}=0.54)$. The results of the previous assessments of training and internship courses in medical sciences universities of the country are as follows: In a study conducted by Sedayi et al. on the satisfaction level of interns with the internship course in the hospital, it was found that they were not satisfied with the number and variety of the patients, medical equipment and welfare facilities [12]. This study is rather in consistent our research.

Soleymani et al. from Tehran University of medical sciences found that the interns and trainees had a favorable attitude towards clinical education in internal wards, 67.04\% and 63.42\% respectively [13].

FarzianPour et al. (2010) reported that training medical students in common practical skills was undesirable [4].

Soleimani et al. from Tehran University of medical sciences in an internal evaluation found that training the interns in communicative skills was desirable with $60 \%$ [13]. These studies are rather in agreement with the present one.

Farzian Pour et al. (2011) reported that the results of investigating the program of the medical students' clinical education in internship courses concerning internal, surgery and maternity wards were undesirable with emphasizing on lack of a lesson plan for the course [4]. The results of the present study are not consistant with 
those of the mentioned research. In 2011, researchers found that the length of the time the medical students were trained in each of the clinical wards of the hospital was 1.38 hours [3]. Findings of the study are not in agreement with those of the present research.

Bazargan et al. from Tehran University and Harden et al. from Dandy University in England have a positive attitude towards the educational evaluation and improvement of the quality of education and research in basic and clinical sciences [6] and [14]. Other studies reported results of the effectiveness assessment by using the CIPP model in employees of Shiraz, Tehran University of Medical Sciences were desirable [15]-[20].

Farzianpour et al. from the Research and Development center of Tehran University of Medical Sciences reported that the results of the evaluation of training and internship courses were desirable. In their study they identified the strong and weak points of the course and finally judged them [8] [13] [15]-[17]. The mentioned study is in agreement with the present one.

\section{Conclusions}

The quality of education in training and internship courses in hospitals affiliated to Tehran University of Medical Sciences (considering inputs, process, product, output, consequence) has been considered rather desirable. The educational managers' function in this university is to develop the process of evaluation.

Considering the results of this study, it seems that it is necessary the offered educational programs in training and internship courses be reviewed. The percentage of the students' satisfaction with the quality of educational programs in training and internship courses was $50.2 \%$ and the mean scores of the evaluation of the offered training and internship programs for theoretical classroom training related to practical training and practical skills were rather desirable. The quality of education in training and internship courses of basic and clinical sciences and also training efficient human forces whose education is consistent with the societies' needs is one of the most important problems which has attracted the attention of many specialists and educational planners in the world and as a result of which different suggestions have been made to solve them. One of the main points common in all the suggestions is that in the process of basic sciences education three important parts are emphasized: knowledge and qualification, mental skills (clinical logic, i.e. analysis of disease conditions) and practical skills (clinical skills). But, what is usually forgotten in the education is skills concerning communication with patients and group work. It is worth mentioning that appropriate communication with the patient, care taken during building up the profile and clinical examination as well as laboratory findings and consulting with the colleagues all causes the treatment to be done in a logical manner.

Although those who are involved in educational plans made necessary efforts to perform educational plans and to use the potential sources in order to achieve the objectives and a high quality education, it is necessary for them to make more efforts. It is suggested that they should make further attempts in this regard.

\section{Acknowledgements}

This study was funded by Educational Development Center (EDC) Tehran University of Medical Sciences. The authors would like to appreciate all faculty members, library staff, students, graduates who participated in this study.

\section{Author's Contribution}

All authors in this paper have contributed in all phases in it’s preparing. First author made final proof reading.

\section{Declaration of Conflicting Interests}

The author(s) declared no potential conflicts of interest with respect to the research, authorship, and/or publication of this article.

\section{Funding}

The author(s) disclosed receipt of the following financial support for the research, authorship, and/or publication of this article: which received financial support from School of Public Health, Tehran University of Medical Sciences. We would like to thank all the managers and users who helped the researchers in this study. 


\section{References}

[1] Worthen, B.R. and Sanders, J.R. (1987) Educational Evaluation: Alternative Approaches and Practical Guidelines. Longman Press, New York, 102.

[2] Popham, W.J. (1975) Educational Evaluation. Hall Press, New York, 61.

[3] Farzianpour, F., Aghababa, S., Delgoshaei, B. and Haghgoo, M. (2011) Performance Evaluation a Teaching Hospital Affiliated to Tehran University of Medical Sciences Based on Baldrige Excellence Model. American Journal of Economics and Business Administration, 3, 277-281. http://dx.doi.org/10.3844/ajebasp.2011.272.276

[4] Farzianpour, F., Emami, A.H., Davari Tanha, F., Hosseini, S. and Farzanehnejad, A.R. (2010) Educational Programs' Quality Assessment Based on Graduates’ Comments. Iranian Red Crescent Medical Journal, 12, 302-307.

[5] Saif, A.A. (2009) Methods of Educational Measurement and Evaluation. Doran Publisher, Tehran, 87-92. [In Persian]

[6] Bazargan, A. (2001) From Internal Evaluation to Quality Assurance in Higher Education: The Case of Medical Education in Iran. Journal of Medical Education, 1, 23-27. [In Persian]

[7] Farzianpour, F., Dargahi, H., Hosseini, S.H., Hosseini, S.S.H. and Hossein, S.H. (2011) Program Evaluation of Health Care Management: Is It Adjusted for Students Needs? American Journal of Economics and Business Administration, 3, 420-424. http://dx.doi.org/10.3844/ajebasp.2011.420.424

[8] Farzianpour, F., Dargahi, H., Eynolahi, N. and Aghababa, S. (2010) Internal Evaluation in Department of Health Care Management in Faculty of Allied Medical Sciences Tehran University of Medical Sciences. Health Information Management, 7, 353-360. [In Persian]

[9] Farzianpour, F., Nedjat, S., Rahimi, A. and Malekafzali, B. (2011) Internal Evaluation of the Department of Epidemiology and Biostatistics of the School of Public Health, Tehran University of Medical Sciences. Journal of the School of Public Health and Institute of Public Health Research, 9, 41-52. [In Persian]

[10] Mansoorfar, K. (2011) Methods of Quality Evaluation Basic Statistic. Amir Kabir, Tehran, 102-110. [In Persian]

[11] Shah, M. and Nair, C.S. (2011) International Higher Education in Australia: Unplanned Future. Perspectives: Policy Practice Higher Education, 15, 129-131. http://dx.doi.org/10.1080/13603108.2011.597888

[12] Sedaie, M., Farzianpour, F., Ghahraman, M.A., Mohammad Khani, G.H., Fattahi, J., Ahmadi, M., et al. (2007) Internal Evaluation of Audiology Department, Faculty of Rehabilitation, Tehran University of Medical Sciences, Iran. Audiology, 16, 1-9. [In Persian]

[13] Soleymani, Z., Mehri, A., Farzianpour, F., Khatoonabadi, A.R., Shahbodaghi, M.R., Khodami, M., et al. (2012) Internal Evaluation Department of Speech Therapy, Tehran University of Medical Sciences. Audiology, 21, 87-95. [In Persian]

[14] Harden, R., Corsby, J., Davis, M.H., Howie, P.W. and Struthers, A.D. (2000) Task-Based Learning: The Answer to Integration and Problem-Based Learning in the Clinical Years. Medical Education, 34, 391-397. http://dx.doi.org/10.1046/j.1365-2923.2000.00698.x

[15] Farzianpour, F., Godarzi, L., Torabipor Hamedani, A., Askari, R. and Hosseini, S.S.H. (2013) Evaluation of Customer Relationship Management in a Teaching Hospital. American Journal of Applied Sciences, 10, 344-352. http://dx.doi.org/10.3844/ajassp.2013.344.352

[16] Farzianpour, F., Emami, S.A.H. and Eshraghian, M.R. (2007) An Evaluation of Basic and Clinical Sciences, Development Project at Tehran University of Medical Sciences. Quarterly Journal of Research in Educational Systems, 1, 4756. [In Persian]

[17] Farzianpour, F., Hosseini, S.H., Amali, T., Hosseini, S.H. and Hosseini, S.S.H. (2012) The Evaluation of Relative Efficiency of Teaching Hospitals. American Journal of Applied Sciences, 9, 392-398. http://dx.doi.org/10.3844/ajassp.2012.392.398

[18] Bastani, P., Amini, A., Taher Nejat, K. and Shaarbafchi Zadeh, N. (2013) Faculty Members’ Viewpoints about the Present and the Ideal Teacher Evaluation System in Tehran University of Medical Sciences. Journal of Advances in Medical Education and Professionalism, 1, 140-147.

[19] Mokhtarzadegan, M., Amini, M., Takmil, F., Adamiat, M. and Sarveravan, P. (2015) Inservice Trainings for Shiraz University of Medical Sciences Employees: Effectiveness Assessment by Using the CIPP Model. Journal of Advances in Medical Education and Professionalism, 3, 77-83.

[20] Rezaee, R. and Shokrpour, N. (2011) Performance Assessment of Academic Departments: CIPP Model. European Journal of Social Sciences, 23, 227-237. 